
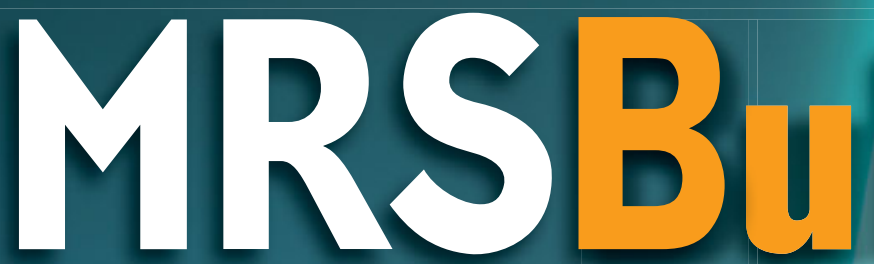

August 2013 Vol. 38 No. 8

www.mrs.org/bulletin

\title{
\begin{tabular}{l|l|l|l} 
MATERIALS RESEARCH SOCIETY \\
Mavancing materials. Improving the quality of life.
\end{tabular}
}

\section{Surface-enhanced Raman speciroscopy:}

\section{Substrates and materials}

ALSO IN THIS ISSUE

Material surfaces under ambient conditions of gases and liquids 


\section{PARTICLE ACCELERATOR SYSTEMS}

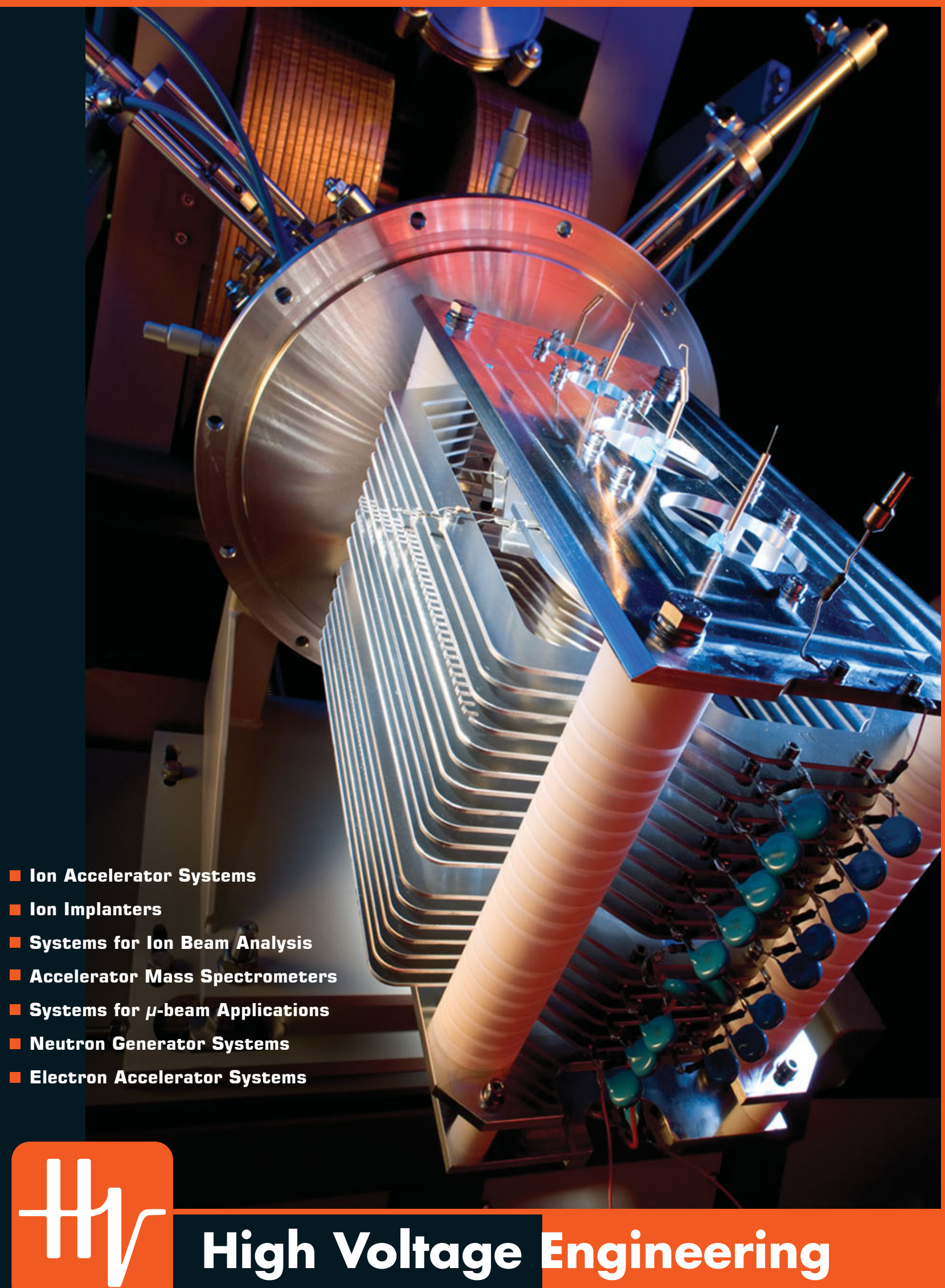

High Voltage Engineering Europa B.V.

P.O. Box 99, 3800 AB Amersfoort, The Netherlands Tel: 31334619741 • info@highvolteng.com

www.highvolteng.com 


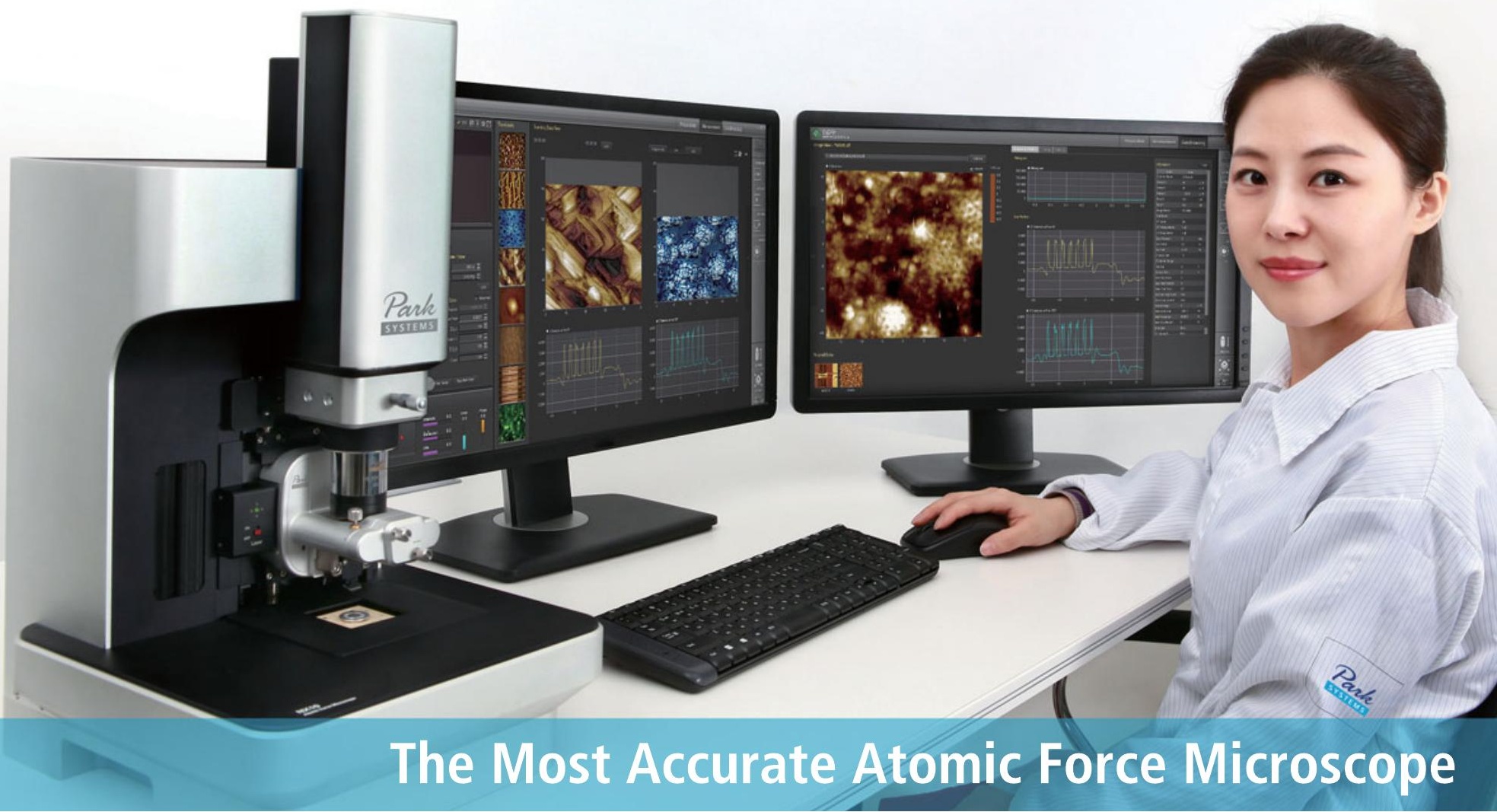

\section{Park NX10 the quickest path to innovative research}

\section{Better accuracy means better data}

Park NX10 produces data you can trust, replicate, and publish at the highest nano resolution. It features the world's only true non-contact AFM that prolongs tip life while preserving your sample, and flexure based independent $X Y$ and $Z$ scanner for unparalleled accuracy and resolution.

\section{Better accuracy means better productivity}

From sample setting to full scan imaging, measurement, and analysis,

Park NX10 saves you time every step of the way. The user friendly interface, easy laser alignment, automatic tip approach, and analysis software allow you to get publishable results faster.

\section{Better accuracy means better research}

With more time and better data, you can focus on doing more innovative research. And the Park NX10's wide range of measurement modes and customizable design means it can be easily tailored to the most unique projects.

To learn more about Park NX10 or to schedule a demo please call: +1-408-986-1110 or email inquiry@parkafm.com
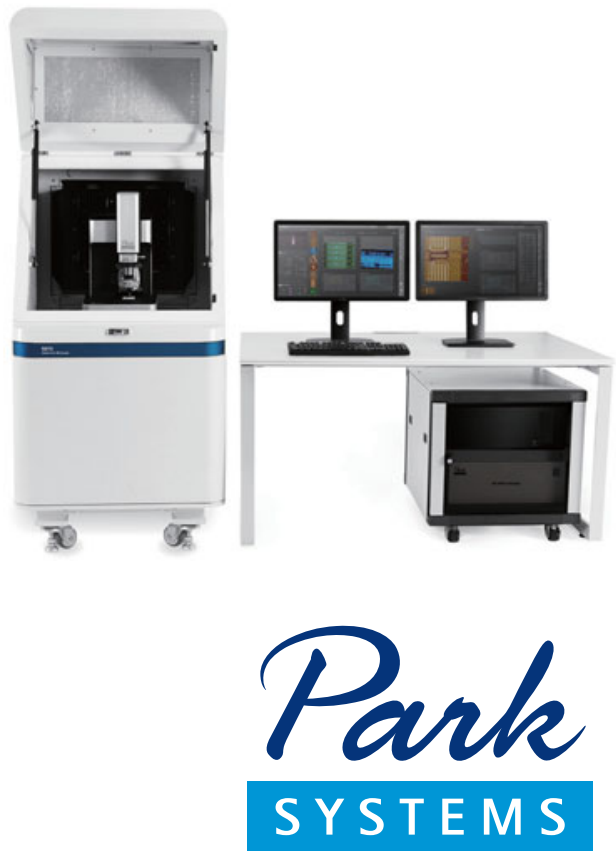


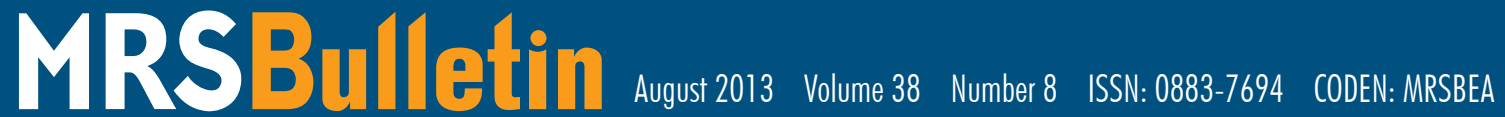
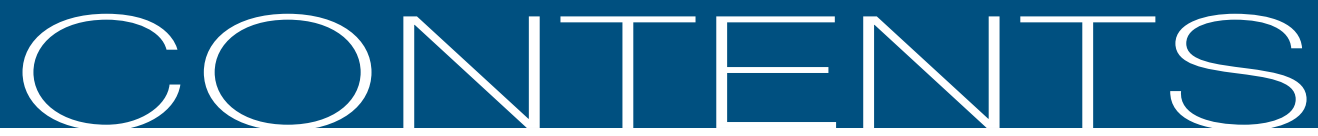

\section{SURFACE-ENHANCED RAMAN SPECTROSCOPY: SUBSTRATES AND MATERIALS}

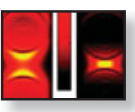

607 Surface-enhanced Raman spectroscopy: Substrates and materials for research and applications

Naomi J. Halas and Martin Moskovits, Guest Editors

\section{Meet Our Authors}

615 High-performance SERS substrates:

Advances and challenges

Bhavya Sharma, M. Fernanda Cardịnal,

Samuel L. Kleinman, Nathan G. Greeneltch,

Renee R. Frontiera, Martin G. Blaber,

George C. Schatz, and Richard P. Van Duyne

625 Molecular imaging with surface-enhanced Raman spectroscopy nanoparticle reporters Jesse V. Jokerst, Christoph Pohling, and Sanjiv S. Gambhir

631 Quantifying SERS enhancements Eric C. Le Ru and Pablo G. Etchegoin

642 Optical activity in single-molecule surfaceenhanced Raman scattering: Role of symmetry

Lev Chuntonov and Gilad Haran

\section{TECHNICAL FEATURE}

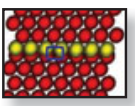

650 Physics and chemistry of material surfaces under ambient conditions of gases and liquids: What's new? 2012 MRS Medal Award Lecture Miquel Salmeron

\section{DEPARTMENTS}

\section{OPINION}

590 Letter from the President

Diversity drives innovation, excellence,

and new discoveries

Orlando Auciello

592 Material Matters

Creating a safety culture in academic laboratories Gary L. Messing

\section{NEWS \& ANALYSIS}

\section{Materials News}

- Big data are shaping the future of materials science Ashley A. White

- "Interaction patchiness" leads to herringbone nanocrystal pattern

- Bubbles in metallic glass facilitate fracture

- Electric field utilized to locally pin magnetic domain walls Steven Spurgeon

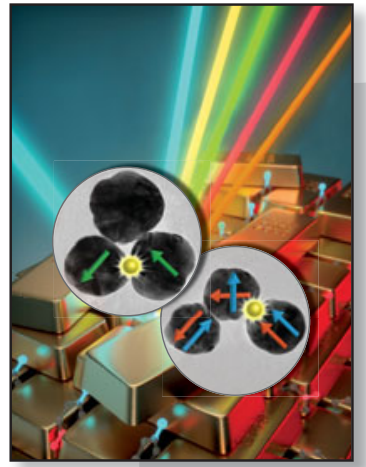

ON THE COVER

Surface-enhanced Raman spectroscopy: Substrates and materials. This issue of MRS Bulletin highlights key field-shaping developments in surface-enhanced Raman spectroscopy (SERS) from a materials perspective. SERS is a highly sensitive vibrational spectroscopy that allows for the detection of analytes at very low concentrations. The cover shows a representation of SERS indicating molecules tucked in among gold "nanobricks." The foreground shows transmission electron microscope images of nanoparticle clusters that were studied optically for single molecule spectroscopy. The yellow particle represents a single molecule SERS reporter occupying the interparticle gap. The arrows drawn on the nanoparticles represent excited plasmon normal modes of the clusters. The background image is courtesy of Peter Allen. See the technical theme that begins on page 607 
$M|R| S \frac{\text { Mdvancing materials. Improving the quallty of life. }}{\text { MATER }}$

www.mrs.org/bulletin

- Quantum dot layer fine-tuned for higher efficiency QLEDs

Christopher Patridge

- 2013 L'ORÉAL-UNESCO Awards for Women in Science honors materials researchers

\section{Science Policy}

- Governments leverage natural resources in transition to hybrid economy Jennifer A. Nekuda Malik

- CSIR to launch titanium pilot plant

- NRC to help Canadian transportation industry reduce vehicle weight

\section{FEATURES}

\section{Beyond the Lab \\ Weaving science into the culture of Uruguay} Zenzile Brooks

664 Image Gallery Look Again

\section{ADVERTISERS IN THIS ISSUE}

Page No

American Elements Outside back cover

American Scientific Publishers ...........

CRAIC Technologies, Inc

High Voltage Engineering Inside front cover Hindawi Publishing Corporation Inside back cover HORIBA Scientific 606 JEOL USA, Inc 597

MMR Technologies, Inc.

National Electrostatics Corp. ...................................... 624

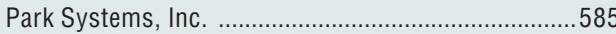

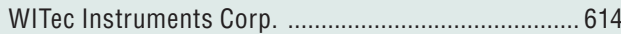

J.A. Woollam Company, Inc. ………………………....599

\section{SOCIETY NEWS}

- JUAMI unites US, African students on studies of materials for energy

- MRS seeks award nominations for 2014

\section{CAREER CENTRAL}




\section{About the Materials Research Society}

The Materials Research Society (MRS), a not-for-profit scientific association founded in 1973 and headquartered in Warrendale, Pennsylvania, USA, promotes interdisciplinary materials research. Today, MRS is a growing, vibrant, member-driven organization of over 16,000 materials researchers spanning over 80 countries, from academia, industry, and government, and a recognized leader in the advancement of interdisciplinary materials research.

The Society's interdisciplinary approach differs from that of single-discipline professional societies because it promotes information exchange across many scientific and technical fields touching materials development. MRS conducts three major international annual meetings encompassing approximately 125 topical symposia, and also sponsors numerous single-topic scientific meetings. The Society recognizes professional and technical excellence and fosters technical interaction through University Chapters. In the international arena, MRS implements bilateral projects with partner organizations to benefit the worldwide materials community. The MRS Foundation helps the Society advance its mission by supporting various projects and initiatives.

MRS publishes MRS Bulletin, MRS Communications, the MRS Online Proceedings Library, Journal of Materials Research, MRS Energy \& Sustainability, and books and textbooks with its publishing partner, Cambridge University Press.

\section{MRS BOARD OF DIRECTORS}

President Orlando Auciello, University of Texas at Dallas, USA Immediate Past President Bruce M. Clemens, Stanford University, USA Vice President and President-Elect Tia Benson Tolle, The Boeing Company, USA

Secretary Sean J. Hearne, Sandia National Laboratories, USA

Treasurer Michael R. Fitzsimmons, Los Alamos National Laboratory, USA Executive Director Todd M. Osman, Materials Research Society, USA

Ana Claudia Arias, University of California-Berkeley, USA Shenda Baker, Synedgen, Inc./Harvey Mudd College, USA David Cahen, Weizmann Institute of Science, Israel

Duane B. Dimos, Sandia National Laboratories, USA Steve Eglash, Stanford University, USA

Chang-Beom Eom, University of Wisconsin-Madison, USA

Susan Ermer, Lockheed Martin Advanced Technology Center, USA

Eric Garfunkel, Rutgers University, USA

Sossina M. Haile, California Institute of Technology, USA

Andrea M. Hodge, University of Southern California, USA

Oliver Kraft, Karlsruhe Institute of Technology, Germany

Hideki Matsumura, Japan Advanced Institute of Science and Technology, Japan

Fiona C. Meldrum, University of Leeds, UK

Eric A. Stach, Brookhaven National Laboratory, USA

Stephen Streiffer, Argonne National Laboratory, USA

Susan E. Trolier-McKinstry, The Pennsylvania State University, USA

\section{MRS OPERATING COMMITTEE CHAIRS}

Academic Affairs M. Stanley Whittingham, SUNY-Binghamton, USA Awards C. Barry Carter, University of Connecticut, USA

Government Affairs Nabil Bassim, US Naval Research Laboratory, USA Meetings Committee David S. Ginley, National Renewable Energy Laboratory, USA

Member Engagement Yves Chabal, The University of Texas at Dallas, USA Public Outreach Aditi Risbud, University of Utah in Salt Lake City, USA Publications Paul McIntyre, Stanford University, USA

MRS OFFICE OF PUBLIC AFFAIRS

Ron Kelley 499 South Capitol St. SW, Suite 600, Washington, DC 20003
Editor

Gopal R. Rao, rao@mrs.org

Managing Editor

Judy Meiksin, meiksin@mrs.org

Technical Editor

Lori A. Wilson, Iwilson@mrs.org

Editorial Assistants

Graeme Lister

Ben Moriarty, moriarty@mrs.org

Mary Wilmoth

Associate Technical Editor

Toby Lockwood

Art Director

Kasia M. Bruniany

Production/Design

Andrea Pekelnicky, Rebecca Yokum,

and TNQ

Production Editor

Catherine Paduani

Science News Editor

Tim Palucka

Principal Development Editor

Elizabeth L. Fleischer

Director of Communications

Eileen Kiley Novak
Guest Editors

Naomi J. Halas and Martin Moskovits

\section{Energy Quarterly}

David Cahen (Chair),

Anshu Bharadwaj, Russell R. Chianelli, George Crabtree, Sabrina Sartori,

Anke Weidenkaff,

M. Stanley Whittingham,

and Steve M. Yalisove

\section{Advertising/Sponsorship}

Mary E. Kaufold, kaufold@mrs.org

Donna L. Watterson, watterson@mrs.org

Member Subscriptions

Michelle Judt, judt@mrs.org

Non-Member Subscriptions

subscriptions_newyork@cambridge.org

\section{EDITORIAL BOARD}

Paul S. Drzaic (Chair), Apple, Inc., USA

V.S. Arunachalam, Center for Study of Science, Technology \& Policy, India

Marie-Isabelle Baraton, University of Limoges, France

Hanns-Ulrich Habermeier, Max Planck Institute for Solid State Research, Germany

Igor Lubomirsky, Weizmann Institute, Israel

Fiona C. Meldrum, University of Leeds, UK

Amit Misra, Los Alamos National Laboratory, USA

Steven C. Moss, Aerospace Corporation, USA

Julie A. Nucci, Cornell University, USA

Linda J. Olafsen, Baylor University, USA

Carol Trager-Cowan, University of Strathclyde, UK

Eric Werwa, Washington, DC, USA

Steve M. Yalisove, University of Michigan, USA

\section{VOLUME ORGANIZERS}

2014 Deborah E. Leckband, University of Illinois at Urbana-Champaign, USA Yuri Suzuki, Stanford University, USA

Enrico Traversa, King Abdullah University of Science and Technology, Saudi Arabia Yonhua Tzeng, National Cheng Kung University, Taiwan

2013 Mark T. Lusk, Colorado School of Mines, USA

Eva Olsson, Chalmers University of Technology, Sweden

Birgit Schwenzer, Pacific Northwest National Laboratory, USA

James W. Stasiak, Hewlett-Packard Co., USA

2012 Lei Jiang, Chinese Academy of Sciences, China

Sergei V. Kalinin, Oak Ridge National Laboratory, USA

Stéphanie P. Lacour, EPFL, Switzerland

Steven C. Moss, Aerospace Corporation, USA

MRS Bulletin (ISSN: 0883-7694, print; ISSN 1938-1425, online) is published monthly by the Materials Research Society, 506 Keystone Drive, Warrendale, PA 15086-7573. Copyright @ 2013 Materials Research Society. Permission required to reproduce content. Periodical postage paid at New York, NY, and at additional mailing offices. POSTMASTER: Send address changes to MRS Bulletin in care of the Journals Department, Cambridge University Press, 100 Brook Hill Drive, West Nyack, NY 10994-2113, USA. Printed in the U.S.A.

Membership in MRS is $\$ 115$ annually for regular members, $\$ 30$ for students. Dues include an allocation of $\$ 29$ ( $\$ 17$ for students) to a subscription to MRS Bulletin. Individual member subscriptions are for personal use only. Non-member subscription rates are $\$ 394$ for one calendar year (12 issues) within North America and $\$ 479$ elsewhere. Requests from subscribers for missing journal issues will be honored without charge only if received within six months of the issue's actual date of publication.

MRS Bulletin is included in Current Contents ${ }^{\otimes}$ Engineering, Computing, and Technology; Current Contents $\circledast /$ Physical, Chemical, and Earth Sciences, the SciSearch ${ }^{\circledR}$ online database, Research Alert田 Science Citation Index ${ }^{\oplus}$ and the Materials Science Citation Index. 300 North Zeeb Road, Ann Arbor, MI 48106, USA. 


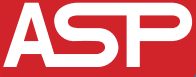

A MERICAN SCIENTIFIC PUBLISHERS

www.aspbs.com

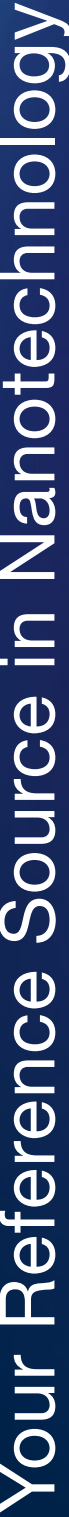

Editors:

Tseung-Yuen Tseng and Simon M. Sze

National Chiao Tung

University, Taiwan

Hardcover, 875 pages

ISBN: 1-58883-250-3 (2012)

\section{NONVOLATILE MEMORIES Materials, Deuices and Applications} 2-Volume Set

Nonvolatile semiconductor memory (NVSM) is one of the most important discoveries in the field of electron devices since the invention of the transistor. Invented by D. Kahng and S.M. Sze in 1967, NVSM, today, is the largest electronic industry in the world. This single invention has subsequently given rise to a large family of memory devices including flash memory and electrically erasable programmable read-only memory (EEPROM). All modern electronic devices, like mobile phones, notebook computers, digital cameras, MP3 music players, personal digital assistants, digital televisions, automotive engine control units, portable medical diagnostic systems, USB flash personal discs, and global positioning systems, are all based on NVSM. In the past 20 years, NVSM's minimum feature length has been scaled down from 0.8 micron to sub- $20 \mathrm{~nm}-\mathrm{a} 40$-fold reduction. Many alternative NVSM technologies are being developed to reduce the size (sub-10 $\mathrm{nm}$ ) and improve device performance. Two-volume set has the most recent advances and future trends in the fields of nonvolatile memories.

\section{KEY FEATURES}

- Two-volume set contains 32 state-of-the-art review chapters

- Edited and written by $\mathbf{7 1}$ world-leading experts working on NVM devices.

- The coverage includes physics, material science, device engineering, and applications of NVM devices.

- Multidisciplinary reference book for engineers and scientists actively working on semiconductor devices.

- A textbook for senior undergraduate and graduate students in applied physics, materials science, electrical and electronics engineering.

\section{CALL FOR PAPERS}

www.aspbs.com/jbn

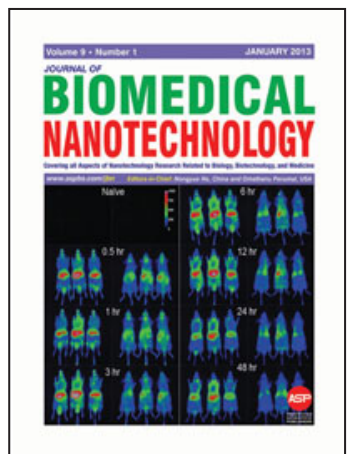

Journal of Biomedical Nanotechnology (JBN) is a peer-reviewed journal focused on the applications of nanotechnology in biotechnology, medicine, and other fields of life sciences.

Impact Factor: $\mathbf{5 . 2 5 6}$

Editors-in-Chief:

Dr. Omathanu Perumal, USA

Submit manuscripts at www.aspbs.com

www.aspbs.com/jnn

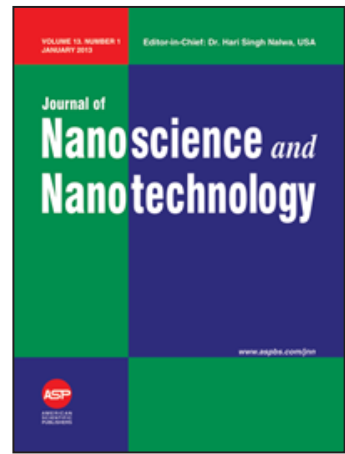

Journal of Nanoscience and Nanotechnology (JNN) is a multidisciplinary peer-reviewed journal covering fundamental and applied research aspects of nanoscale science and technology dealing with all disciplines of physical sciences, engineering and medicine.

Editor-in-Chief:

Dr. Hari Singh Nalwa, USA
wWw.asplbs.com/jctn

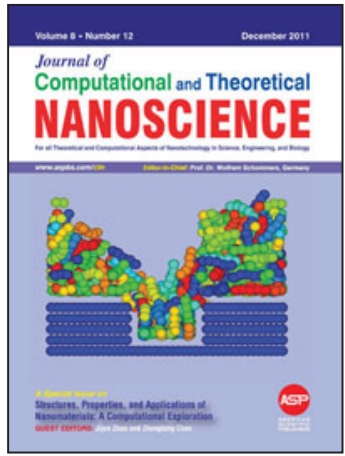

Journal of Computational and Theoretical

Nanoscience (JCTN)

publishes peer-reviewed papers focused on computational and theoretical aspects of nanotechnology and nanoscience.

\section{Editor-in-Chief:}

Prof. Dr. Wolfram

Schommers, Germany

\section{ORDER FROM}

